\title{
Exploring assessment factors contributing to students' study strategies: Literature review
}

\author{
HANAN M. AL-KADRI ${ }^{1}$, MOHAMED S. AL-MOAMARY ${ }^{1}, \mathrm{CHRIS}^{\text {ROBERTS }}{ }^{2}$ \& \\ CEES P.M. VAN DER VLEUTEN ${ }^{3}$ \\ ${ }^{1}$ King Saud bin Abdulaziz University for Health Sciences, Saudi Arabia, ${ }^{2}$ University of Sydney, Australia, \\ ${ }^{3}$ University of Maastricht, The Netherlands
}

\begin{abstract}
"Assessment steers students' learning" is a statement that has been used repeatedly without solid evidence in the literature. This manuscript aims to evaluate the published literatures on the effect of teaching learning environment in particular, the implemented assessment on students' learning approaches. A literature review was performed on the effect of assessment on students learning approaches. English language literatures were searched in Pubmed, PsycINFO, and Medline without restriction to type or date of publication. Reviewing the literature, the most prominent identified theme was assessment function characterized in summative and formative assessment and general effect of assessment on students' learning approaches. The literature review has pointed clearly to the complexity of the relationship between learning environment, students' perceptions of assessment demands, and students' approaches to learning. Many factors (extrinsic and intrinsic) were theoretically proposed to mediate students' approaches to learning in response to their assessment. However, few of these factors were researched in the published literature. Formative assessment is likely to contribute to students' deep approach to learning while summative is likely to contribute to their surface approach. However, these effects are not definite and further research about the complex relationship between assessment and students' learning is required.
\end{abstract}

\section{Introduction}

Assessment steers learning is a statement that has been presented by Newble (1988) as early as 1983. Since then, this statement is viewed as well-proven despite the fact that supportive evidence was quite limited. Historically, adopting the psychometric theories for several decades has focused on factors and indicators, like reliability and validity that are related to assessment quality (Schuwirth \& van der Vleuten 2004). The implementation of such psychometric theory has resulted in summative assessment having higher importance in comparison with formative assessment. Therefore, teachers' test selection was directed to achieve high test quality rather than focusing on the test educational impacts (Schuwirth \& van der Vleuten 2004). Teachers have also consequently avoided practicing a bi-directional process with their students to enhance, recognize, and respond to students' learning (Cowie \& Bell 1999). Moreover, they have made little effort to implement formative assessment as a method to help the learning process (Black \& Wiliam 1998b; Reay \& Wiliam 1999). Assessment then became a method to rank students or decide their pass or fail rather than an instrument to enhance their learning. Its influence was mainly on assessment of students learning rather than assessment for students learning enhancement.

In contrast to the psychometric theory, assessment for learning moved the educational focus from an individual

\section{Practice points}

- Assessment steers students learning however, its effect is not always positive.

- Formative assessment is likely to contribute to students deep approach to learning. Its positive impact is correlated with successful culture change.

- Summative assessment is likely to contribute to students surface approach to learning. Its negative impact is correlated with the magnitude of the consequences associated with its implementation.

- Several assessment-related extrinsic and intrinsic factors were theoretically proposed to mediate students' approaches to learning. Not all of these factors were validated by research.

- At the moment, drawing a firm conclusion on different assessment factors contributing to students' learning approaches is difficult, further research is needed.

instrument into programmatic assessment where we tend to use multiple assessment instruments each of which is directed to cover a particular aspect of the intended educational objectives (Van der Vleuten \& Schuwirth 2005; Schuwirth \& Van der Vleuten 2011). In this approach, the old assessment tools are not replaced with the new ones, rather they are supplemented with tools that focus more on the tests

Correspondence: H. M. Al-Kadri, College of Medicine, King Saud bin Abdulaziz University for Health Sciences, PO Box 57374 , Riyadh 11574 , Kingdom of Saudi Arabia. Tel: 00966-1-4632717; fax: 00966-1-4632717; email: halkadri@gmail.com 
educational impact (Prescott et al. 2002) and utilize formative assessment to enhance students learning. Assessment for learning was then thought to direct students' studying toward deep approach to learning.

Research into student learning initially built up evidence about the relationships of motivation and study methods with academic performance (Biggs 1970, 1976; Entwistle \& Entwistle 1970; Schmeck et al. 1977). Researchers stressed the importance of the student's own effort and application in determining levels of academic achievement that shifted the responsibility for high achievement to student's shoulders (Biggs 1970, 1976; Entwistle \& Entwistle 1970).

The initial learning style inventories have emphasized the relative stability of students' learning approaches and were used to predict students' future academic performance (Biggs 1970, 1976; Entwistle \& Entwistle 1970; Schmeck et al. 1977). Based on the early inventories, students' learning approaches were found to reflect three basic learning models (Broadbent 1966): (1) surface learning, involving "repetition of analyses already carried out" and usually directed at reproducing information; (2) deep level learning, using "a greater degree of semantic or cognitive analysis" usually aimed at gaining insight and (3) "assessment driven category," named a strategic approach to learning. Researches on students' learning approaches have progressed to focus more on the effect of the teaching-learning environment (Biggs 1999) and have investigated the different ways students interpret the requirements of a task within a specific learning context (Marton \& Saljo 1997). Students learning approaches were found to be unstable, swinging between superficial, deep and strategic approaches as a result of different contextual and personal factors. Moreover, inventories have emphasized students' selfconscious reflection on learning, drawing on the ideas of "meta-cognition" and "self-regulation" (McKeachie 1990; Vermunt 1996, 1998). Students learning approach categorizations were then modified to deep, reflective, and elaborative approaches and superficial with serial, reiterative, or rehearsal approach. A third approach of learning that describes methodical, well-organized studying linked to effort that is done by the students based on certain motivation and aiming for certain achievement such as passing exam or achieving high scores or leaving good impression and obtaining certain recommendation. This particular strategy is called effort and achievement motivation learning strategy and has replaced the strategic strategy approach.

Several researches have been published aiming to explore the relation between assessment and learning. However, until recently, literature was not firmly sure of the effect of assessment on students' learning (Norman et al. 2010). The aim of this literature review is to explore and synthesize the published literatures on the effect of teaching learning environment in particular the implemented assessment on students' perception of their learning and their study strategies.

\section{Methods}

A literature review was carried out to identify and analyze results of what have been published on effects of assessment on students' approaches to learning. The search was conducted through peer reviewed journals and the used searching terms were assessment and study strategy, assessment and learning approach, assessment and deep learning, assessment and surface learning. Pubmed and Medline engines were searched as well as PsycINFO. The only restriction was applied to English language and human literature. Otherwise, there was no restriction to the type of articles or the date of publication. References of all relevant articles were reviewed and experts in the field were contacted to explore the presence of relevant work to be reviewed.

As the collected data were heterogeneous, the identified literatures were clustered under the common themes that were recognized. Therefore, the identified literatures were synthesized under the prominent theme of "summative" and "formative" assessment. Further literatures that have discussed the "general effect of assessment on students learning" were synthesized under this title.

\section{Results}

The majority of identified literatures discuss general assessment factors contributing to students' approaches to learning (Tang 1994; Scouller 1996; Santy \& Mackintosh 2000; Nijhuis et al. 2005; Tiwari et al. 2005; Segers et al. 2006, 2008; Struyven et al. 2006; Gijbels et al. 2008; Shen et al. 2008; Al Kadri et al. 2009, 2011b; Kadri et al. 2011). They also focus on various aspects of either summative assessment (Leung et al. 2008; Cilliers et al. 2010, 2011) or formative assessment (Black \& Wiliam 1998a; Tillema 2001; Sluijsmans et al. 2002; Rushton 2005; Baeten et al. 2008; Koh 2008) or were in the form of literature review (Dochy et al. 2006; Broekkamp Hein et al. 2007).

A small number of literatures addressed the swinging study strategies practiced by the students between surface and deep approaches to learning, e.g., Al Kadri et al. (2011b), Mattick and Knight (2007), Mattick and Knight (2009), and Newble and Jaeger (1983). Moreover, there were scarce literatures that assessed circumstances or conditions under which students reacted to their assessment and changed their learning approach whether toward deep or surface approach to learning, e.g., Kadri et al. (2011) and Al Kadri et al. (2009, 2011b). Furthermore, there were even more scarce literatures that have discussed the role of assessment in driving students' learning in a clinical teaching context (Al Kadri et al. 2009, 2011a, 2011b; Kadri et al. 2011).

Broekkamp Hein et al. (2007) have developed a theoretical model that integrates various factors which seem relevant to learning strategy adaptation in students' test preparation, including the teacher's intended task demands, students' perceptions of these demands, students' personal goals for learning, and their ability to adapt and implement strategies. The basis of this theoretical model is the construction of strategy adaptation as used in basic cognitive psychology research (Schunn \& Reder 1998; Luwel et al. 2005). There was no reliance on medical education literature or on literatures that have discussed students' assessment in a clinical environment.

In this theoretical framework, it was acknowledged that study strategy adaptation might include adaptation to both 
external and internal task characteristics. While the external task characteristics have included the task implementation environment and its context, internal task processes have included students' ability to adapt various learning strategies, their perception of the task demand and task disposition. In fact research on strategy adaptation in test preparation reported diverse results (Broekkamp Hein et al. 2007). These results varied across disciplines and between experimental and authentic researches. They also differed with the variations of students' grades, between experimental and authentic research environments, different data collection methods and variation in the environmental and individual conditions under which students were expected to adapt their learning strategies to task demands.

Recent research published by Al Kadri et al. (2009, 2011b) and Kadri et al. (2011) have validated few areas of applicability of factors presented in Broekkamp's theoretical framework in a clinical education field. In their work, they have identified ways through which these theoretical factors affect students' approaches to learning, the direction of these effects, contributing factors and how and why they affect students' strategy adaptation. They have assessed various extrinsic factors such as education and students' culture, curriculum objectives, clinical supervisor and supervision and intrinsic factors such as task demand, motivations, and task goals. What was prominent in Al Kadri's findings is that though assessment was found to drive students learning, this was not always a positive drive. Students' learning approaches in response to their assessment were not stable and were swinging between surface, deep and achievement motivation strategies. These swinging effects have varied between studied institutions, different studied students, the students themselves, and the assessment function whether summative or formative.

\section{Summative assessment and students' approaches to learning}

Students cannot escape the impact of summative assessment (Boud 1995; Table 1). The design of such assessment is more typically informed by psychometric rather than learning considerations, i.e., usually it is designed to assess students' learning rather than to enhance it. In contrast to formative assessment, summative assessment is used to measure students' achievement or failure and judge their performance. It has a dominant effect on students' learning (Knight 2001). However, the degree of its impact on students' learning is strongly correlated with the magnitude of the severity of consequences associated with its implementation (Al Kadri et al. 2011b; Cilliers et al. 2011).

Cilliers et al. (2010, 2011) have published two exploratory studies aiming to probe the mechanisms by which assessment has impacts on learning. He focused on how various dimensions of summative assessment bring about its influence on students' learning. A grounded theory was adopted to conduct unstructured interviews with students in a South African medical school. In these two researches, it was noted that learning behaviors of the students are influenced by their appraisal of the impact of assessment and appraisal of their learning response. Moreover, it was found that the negative effect of summative assessment on students learning is overwhelming and outweighs other aspects of assessment effects if not designed in harmony with the overall program. Al Kadri et al. (2009, 2011b) have assessed qualitatively students' perceptions of their implemented assessment and the resulting study strategies. In these researches, they have indicated that summative assessment is strongly influencing students learning leading to more tendencies toward surface approach to learning or in the best case scenario it leads to achievement motivation study strategy rather than directing students toward deep learning approach. However, Al Kadri has indicated that the effect of assessment is not standing alone and it is strongly affected with other different contextual factors such as students' cultural background, job opportunities, and health care system. For example, students from multi-culture background such as those living in Sydney, Australia and those who were within health care setup that rely mainly on outcomebased assessment rather than students' summative assessment results were more adaptive to summative assessment induced

Table 1. Summary of literatures that have discussed effects of summative assessment on students learning approaches.

\begin{tabular}{|c|c|}
\hline References & Aim of the research \\
\hline Cilliers et al. (2011) & $\begin{array}{l}\text { To assess summative } \\
\text { assessment impact on } \\
\text { student learning? }\end{array}$ \\
\hline Cilliers et al. (2010) & $\begin{array}{l}\text { To probe how various } \\
\text { dimensions of summative } \\
\text { assessment do affect } \\
\text { various dimensions of } \\
\text { learning? }\end{array}$ \\
\hline Leung et al. (2008) & $\begin{array}{l}\text { To examine the effect of high } \\
\text { quality multiple-choice tests } \\
\text { on the learning approaches } \\
\text { of students enrolled in a } \\
\text { mental health nursing course }\end{array}$ \\
\hline
\end{tabular}

\section{Method}

A qualitative research that adopted a grounded theory was conducted at a South African medical school with a 6 -year, modular

A qualitative research that has adopted a grounded theory was conducted at a South African medical school with a 6year, modular

The revised two-factor study process questionnaire was used. Data were collected from 136 students in a higher diploma nursing program and 142 baccalaureate nursing students

\section{Conclusion}

This study shows how overwhelming is the impact of summative assessment on students' learning. Summative assessment is likely to overwhelm other aspects of assessment and learning if not designed in harmony with the overall education program

Students' learning behavior is influenced by appraising the impact of assessment; appraising their learning response; their perceptions of agency; and various contextual factors

A general increase in students' surface approach and a decrease in their deep approach to learning were realized. These changes in students approaches were noted between the pre-test (beginning of course) and post-tests (completion of the course) 
stress and considered it as a positive drive to their learning. On the contrary, students who were affected by summative assessment performance consequences were under more stress that has lead to patchy and superficial learning and turned those students into mark hunters. The results of both authors Al Kadri and Cilliers are stressing on the need to accommodate any assessment program within the students' culture and educational environment. In their opinion, such accommodation will enable health educators to get the best of their students' perceptions and direct their studying positively toward deeper approach to learning.

Leung et al. (2008) have assessed the role of appropriate assessment program design for nursing students on promoting students' deep approach to learning. They used a multiplechoice question tool to assess its summative use on nursing students' learning approaches. Leung noticed a general increase in the surface approach and a decrease in the deep approach to students' learning between the pre-test (beginning of course) and post-test (completion of the course). It was found that the multiple-choice question assessment tool enhanced students' surface approach to learning. Whether this surface approach was affected by the assessment tool used or the summative effect is not clear. However, Leung et al. (2008) proposed that it was likely that various other contextual factors had contributed to this result and affected students' approach to learning. These "theoretically suggested factors or un-experimented factors namely students' work load, curriculum design and teaching methods" were part of Broekkamp Hein et al. (2007) extrinsic factors that were presented in their theoretical framework. To justify Leung and Broekkamp's suggestions of the responsibility of these factors on the effect of assessment on students approaches to learning in medical education setup, further research is needed.

\section{Formative assessment and students' approaches to learning}

Black and Wiliam (1998a) in their review article, examined over 250 studies on formative assessment (Table 2). Their metaanalysis of these articles revealed that formative assessment resulted in positive benefits to learning and that good feedback could make a considerable difference to the quality of students' learning. Moreover, Santy and Mackintosh (2000) in another review that assessed the learning process in nurses education, seconded Black and Wiliam's results and recommended that formative assessment be considered as an integral part of students education rather than as a means of measuring ability. They have emphasized the use of different methods to assess students formatively with the intention of engaging these students in learning activities that address gaps in knowledge and provide feedback on their learning achievement. Therefore, they have recommended the use of assessment to enhance students' learning rather than to assess their achievement. Further review on the effect of formative assessment on students' learning was done by Koh (2008) who have summarized the benefits of formative assessment implementation to: (1) students' development of deep thinking, (2) maintenance of students' motivation, and (3) enhancement of students' self-esteem and encouragement of self-regulated learning.
However, while confirming both Black's and Santy's results in formative assessment positive outcome on students' learning, Koh has emphasized the role of students and teachers' understanding of both assessment environment and assessment process to achieve desired educational results.

Teachers' awareness of the inter-relationship between the three areas of "assessment, curriculum, and pedagogy" was further stressed by Klenowski (1996) and was identified to influences students' deep approach to learning. Teacher's personality, availability, training, and effectiveness as a role model carried a positive impact on students' approaches to learning. Despite this strong emphasis on the role of teachers in students' learning, when teachers have a simple rather than conventional idea of stimulating students' studying, they prefer summative assessment to formative as a factor that leads to deeper approach to learning. Those teachers do believe that the only and first priority in designing an assessment program is to serve the purpose of students' accountability, ranking, and certifying competence. On the other hand, they deny its remarkable effect on promoting students' learning. It appears that teachers' education, experience, and cultural backgrounds have an influence on how they perceive different assessment programs and how they respond to the implemented assessment whether summative or formative (Al Kadri et al. 2009, 2011b; Kadri et al. 2011).

In fact, most of the literatures on formative assessment are linked more strongly to teaching rather than learning (Tillema 2001; Rushton 2005). Edstrom et al. (2006) suggest that students' perception of assessment depends less on how it is actually designed, but more on how it is presented to them. However, some teachers view assessment as a process they go through after finishing their teaching rather than something central to learning (Koh 2008). As teachers can alter the students' perception of assessment, it is worthwhile to spend enough time to explain clearly to these teachers the intention of formative assessment and their significant influence on students learning approaches.

Although formative assessment had been found to be linked to students' deep approach to learning, based on Rushton's (2005) synthesis of educational literature to healthcare, it was questionable if the required paradigm shift in assessment culture has occurred. Rushton's analysis suggests that further changes are required in assessment practice. These changes should enable effective development of formative assessment involving the consideration of teaching and learning strategies, in particular, the provision of feedback.

After 3 years of Rushton's plea, Baeten et al. (2008) published their experiment on the dynamics of students' approaches to learning and their assessment preferences in a portfolio-based learning environment. It appears that despite Rushton's recommendations, similar findings were achieved by Baeten. The cultural change did not occur and Baeten's students' learning processes were goal-oriented and were individually different because of students' personal learning goals and action plans. A similar finding was reached later on by Al Kadri et al. (2011a, b) where educational culture and students' and teachers' beliefs of the role of assessment have significantly affected students' perception of formative assessment and their study approaches. 
Table 2. Summary of literatures that have discussed effect of formative assessment on students' learning approaches.

$\begin{array}{ll}\text { References } & \text { Aim of the research } \\ \text { Baeten et al. (2008) } & \begin{array}{c}\text { To access the relationships } \\ \text { between experiences with } \\ \text { portfolio assessment, stu- } \\ \text { dents' approaches to learn- } \\ \text { ing and their assessment } \\ \text { preferences }\end{array} \\ \text { Al Kadri et al. (2011a, b) } & \begin{array}{c}\text { To study the relationship } \\ \text { between students' percep- } \\ \text { tions and practices of self- } \\ \text { assessment and their study } \\ \text { strategies within a commu- } \\ \text { nity of clinical practice } \\ \text { To refocus on the purpose of } \\ \text { formative assessment }\end{array}\end{array}$

Black and Wiliam (1998a,b) To perform meta-analysis on the effect of formative assessment on students learning and achievement

Sluijsmans et al. (2002)

To study the influence of pee assessment training on the peer assessment skills as well as on students' test performance

Tillema (2001)

To test students perception of Portfolio implementation

Rushton (2005)

To evaluate the pedagogical implications of formative assessment to deep learning. Moreover, to explore feedback as central to formative assessment and its links to deep learning

\section{Method}

A total of 138 first-year professional bachelor's degree students in office management were included. Assessment and approaches to learning preferences were measured by means of the Revised Two-Factor Study Process Questionnaire and the Assessment Preferences Inventory

Qualitative study through interviews held with three different cohorts of undergraduate medical students was performed. These students were exposed to three different education contexts

Through literature review, benefits of formative assessment and its pedagogical implications on deep learning, motivation and self-esteem, self-regulated learning, and employability were examined

Review article that examined over 250 studies of formative assessment

A total of 93 second-year students in a teacher training college were assigned to either an experimental or comparison group. Experimental group were trained in defining performance criteria, giving feedback, writing assessment reports, and using peer assessment tasks. Comparison group students were not trained

The study was conducted in the context of a training program for small business and retail managers. Three different portfolios were used to collect data on progress in entrepreneurial competencies for three different samples. The 137 participants in the study were asked about the perceived benefits and problems while collecting and learning from the portfolio

Literature review and synthesis of the literature

\section{Conclusion}

Individual differences between the students learning processes are present. These differences are influenced by the students' personal learning goals and action plans that students had formulated in advance. In general, there are significant correlations between a deep approach to learning and a preference for tasks that require higher-order thinking

The theoretical advantages linked to the self-assessment process are a result of its feedback component rather than the practice of self-assessment isolated from feedback. Feedback is linked to deeper approach to learning

The article findings identify key themes in the form of benefits of formative assessment with feedback. These are development of deep thinking, maintenance of motivation, self-esteem, and encouragement of self regulated learning.

Formative assessment results in positive benefits on learning and good feedback can make a considerable difference to the quality of students' learning

Training on utilizing peer assessment and feedback lead to better performance, better final scores and better quality of assessment performance

There is clear variations in performance change among students who utilized different portfolio types. The reflective portfolio shows the most gains, correlating with the highest functional feedback as perceived by the students. The dossier portfolio and course-related portfolio show lower levels of behaviora improvement

The existing evidence suggests that further changes are required in practice to enable effective development of formative assessment involving the consideration of teaching and learning strategies, in particular the provision of feedback. To ensure the success of developing formative assessment, it must be established within models of pedagogy. This necessitates a move away from the current emphasis on products of assessment to an emphasis on the processes of assessment and learning
Overall, it must be stated that literatures highlight many claims regarding the positive effects of formative assessment on learning. These claims might be "overstated and undertheorized" particularly when considering students' approaches to learning (Torrance \& Prayor 1998). Further work is recommended to put the existing theories into practice. Moreover, it appears that more emphasis is needed on the role of culture and culture change to achieve the positive learning effects of formative assessment. This change is required as a pre-requisite to formative assessment implementation.

\section{General assessment effects on students' approaches to learning}

Students might have a predisposition or preference to either deep or surface learning approaches (Biggs 1993; Table 3). This preferred learning approach can be 
Table 3. Summary of literatures that have discussed general effect of assessment on students' learning approaches.

References

Al Kadri et al. (2009)

Al Kadri et al. (2011b)

Gijbels et al. (2008)

Tang (1994)

Scouller (1996)

Segers et al. (2006)

Santy and

Mackintosh (2000)

\section{Aim of the research}

To explore how and why students differ in their approaches to learning, how assessment affects deep learning, and which barriers stand in the way of good assessment and learning

To explore the effects of clinical supervision and assessment characteristics on the study strategies used by undergraduate medical students during their clinical rotations

To investigate students' perceptions of assessment and the resulting learning approach

To answer the following questions: (1) Do students who participate in a constructivist learning environment change their perception of assessment demands towards more deep level? And do they change their

approaches to learning? Finally, is there a relation between students' change in approaches to learning and the perceptions of the assessment demands?

To assess students approaches to learning in response to new assessment method

To assess effects of the implemented assessment on students' approaches to learning

To explore the conditions for assessment to steer learning

To argues for a change in emphasis, so that assessment is seen as a part of learning, rather than a series of arbitrary hurdles to be negotiated
Method

Qualitative, study utilizing interviews with students and teachers was done

Qualitative study utilizing interviews with students and teachers to explore students' and clinical teachers' perceptions and interpretations of factors influencing students' study strategies

Qualitative interviews were conducted with students and clinical supervisors from Sydney Medical School and King Saud bin Abdulaziz University for Health

Sciences in Saudi Arabia

Within constructivist learning environment, students were asked to answer a questionnaire during the first, the second, and the final lesson of the "Education and psychology" course. One questionnaire measured their approaches to learning and the other their genera perceptions of the assessment demands

Qualitative research was done where students were interviewed following the implementation of new teaching approach (writing assignments)

A total of 140 first-year Sociology students have answered questionnaires on students' approaches to learning and their perceptions of the intellectual abilities or skills being assessed within two assessment contexts of the same course

A questionnaire was used for a second year "international business strategy" course in which two different task demands were implemented, the original task and the re-designed task that was thought to induce deeper approach to learning

Review article

\section{Conclusion}

Assessment affects students' perceptions of learning and how they learn. These effects are not uniformly positive. The predominantly summative assessment program is offering little inducement to engage in deep learning

Factors identified to play a role in students' adoption of different study approaches were clinical supervisors and supervision, stress and anxiety and assessment. Moreover, teachers are playing a key role, as assessors, clinical supervisors and as a source of stress to students. The effects of these factors lead students to swing between different learning approaches

A combination of formative and summative assessment based on learning objectives is required to enhance positive impact on students' learning. This combination should take into consideration students' cultural background, values, and the implemented education system.

The results indicated that students do change their perceptions of assessment demands toward more deep level in response to constructivist learning environment. However, this change is not accompanied with similar change in their approach to learning. On the contrary, students seem to develop more surface approaches to learning during the course. Students' approach to learning at the beginning of the course seems to have a higher impact on the extent to which they change their approach to learning than how students perceive the demands of the assessment

High-level strategies such as understanding, application of information, relating to other subjects, and previous knowledge are requirements perceived to be necessary for all assessment conditions. However, lowlevel strategies such as rote learning, memorization, and reproduction are perceived to be relevant only to the test condition.

Assessment method strongly influence the way students learn and prepare for assessment tasks

The results indicate that the students in the original course adopt more deep approaches to learning and less surface approaches to learning than the students in the re-designed course. There are no significant differences between both groups of students in the intended approaches to learning as well as in their perceptions of the assessment demands.

Assessment should be considered as an integral part of the learning process in nurse education rather than just a means of measuring ability or a series of hurdles to be overcome 


\section{Table 3. Continued.}

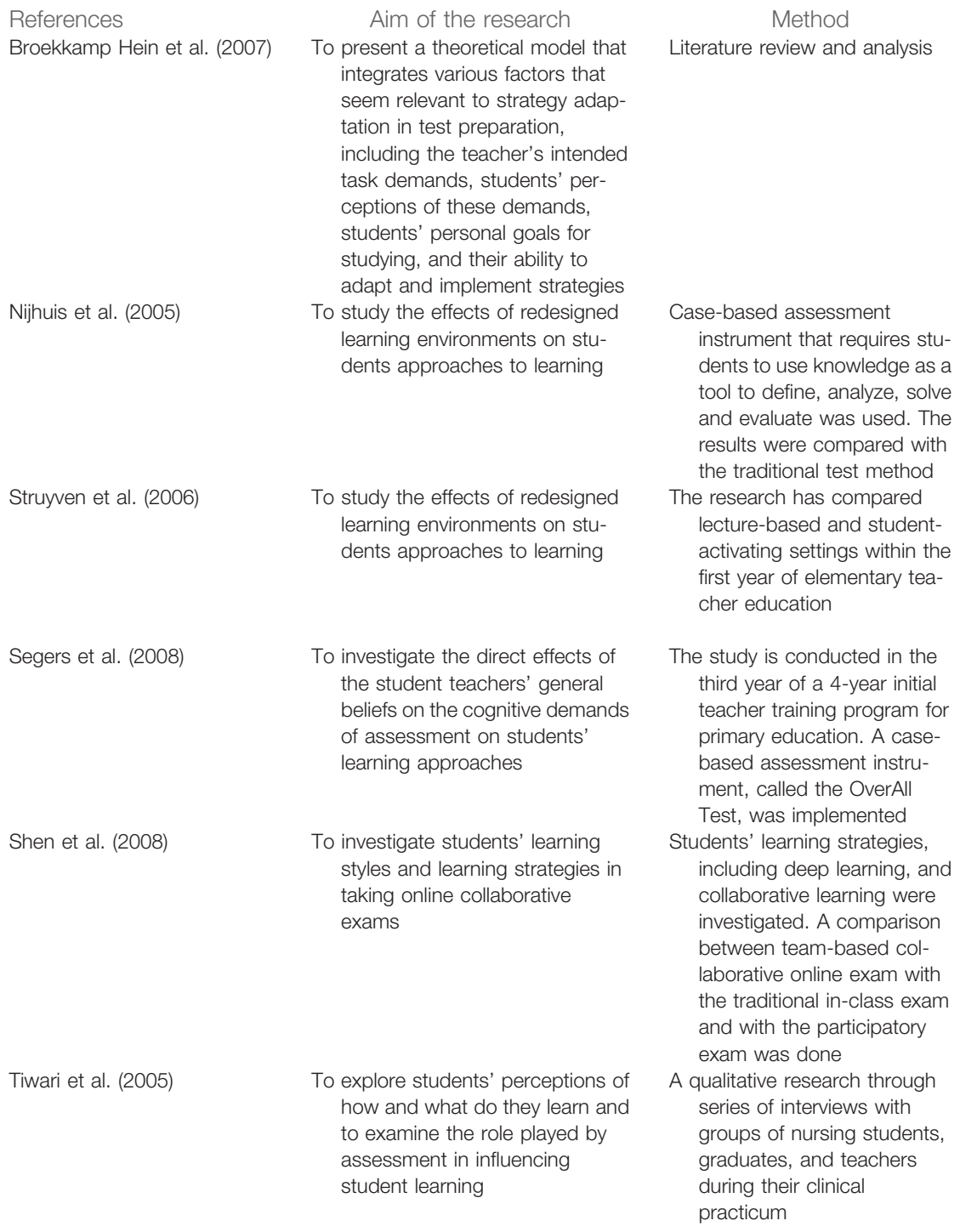

References

Broekkamp Hein et al. (2007)

Struyven et al. (2006)

Segers et al. (2008)

Tiwari et al. (2005)

Aim of the research

To present a theoretical model that integrates various factors that seem relevant to strategy adaptation in test preparation, including the teacher's intended task demands, students' perceptions of these demands, students' personal goals for studying, and their ability to adapt and implement strategies

To study the effects of redesigned learning environments on students approaches to learning

To study the effects of redesigned learning environments on students approaches to learning

To investigate the direct effects of the student teachers' general beliefs on the cognitive demands of assessment on students' learning approaches

To investigate students' learning styles and learning strategies in taking online collaborative exams

To explore students' perceptions of how and what do they learn and to examine the role played by assessment in influencing student learning

Method

Literature review and analysis instrument that requires students to use knowledge as a tool to define, analyze, solve and evaluate was used. The results were compared with the traditional test method

The research has compared lecture-based and studentactivating settings within the first year of elementary teacher education

The study is conducted in the third year of a 4-year initial teacher training program for primary education. A casebased assessment instrument, called the OverAll Test, was implemented

Students' learning strategies, including deep learning, and collaborative learning were investigated. A comparison between team-based collaborative online exam with the traditional in-class exam and with the participatory exam was done

A qualitative research through series of interviews with groups of nursing students, graduates, and teachers during their clinical practicum

\section{Conclusion}

Various extrinsic and intrinsic factors are presented in Broekkhamp theoretical model that are contributing to students learning approach and study strategy adaptation in response to task demands

The results show clearly that regardless the task employed, students who express their intentions to employ certain learning strategy perceive the assessment demands as such and employ a related learning strategy

The results indicate that the introduction of new modes of assessment, does not directly lead to desired changes in student learning. Various factors might mediate the effect of new learning environments on student learning

Students' perception of the deep-level demands of the OverAll Test mediates the effect of their beliefs on the adoption of deep approaches to learning

Collaborative examinations significantly reduce surface learning in exam study, enhance interactions and the sense of an online learning community, and increase perceived learning. Moreover, learning predispositions were significantly correlated with exam study strategies

Students' learning during the clinical practicum is, to a large extent, affected by their perceptions of the assessment tasks. As a result, they adopt a surface approach to learning and focus on preparing for the assessment tasks modified by the learning environment for individual courses or for particular tasks (Ramsden 1984). For example, students may vary in their approaches to learning when trying to cope with assessment tasks. Learning approaches, therefore, are not stable (Marton \& Saljo 1976; Al Kadri et al. 2011b)

The direct effects of the students' general beliefs on the cognitive demands of assessment and students' learning approaches were investigated by Segers et al. (2008). Segers found that students' perception of the deep-level demands has mediated their adoption of deep approaches to learning. For some students, deep approach to learning is perceived as requirements for all assessment conditions (Tang 1994). However, this perception is not always paralleled by similar change in students' approach to learning (Gijbels et al. 2008). These approaches are affected by students' pre-intended learning strategies at the beginning of a study course (Nijhuis et al. 2005; Segers et al. 2006; Gijbels et al. 2008). This intention is under influence of various factors including assessment that may strongly affect the way students prepare for their tasks (Scouller 1996; Struyven et al. 2006; Broekkamp Hein et al. 2007).

In general, when students plan to learn and understand, they tend to use a deep approach to learning, but when they prepare for their exams, regardless of their perception of learning approaches, they are likely to use less of deep approach to learning and more of surface approach to learning (Tang 1994). This is found to be true even with the introduction of new modes of assessment (Struyven et al. 2006) that requires more deep thinking and analytic approach and it is also true even with the change of learning environment (Shen et al. 2008) through education, explanation, and orientation on the benefits of certain assessment tool or certain learning approach (Al Kadri et al. 2011a). These facts add more priority to the need for changing education culture in order to enhance students learning. 


\section{Conclusion}

Even after almost a century of research, efforts to positively influence learning through assessment do not always yield to encouraging results. This reflects how little we know about the complex relationship between assessment and students' learning and highlights the urgent need to conduct further research to explore this area.

The previous literature review has pointed clearly to the complexity of the relationship between the learning environment, the students' perceptions of assessment demands, and students' approaches to learning. This complexity indicates that many factors (extrinsic and intrinsic) are mediating students' approaches to learning in response to their assessment. It appears also that drawing a firm conclusion on different assessment factors contributing to students' learning approaches is difficult.

Assessment drive students learning, but this drive is not always toward positive direction. Formative assessment is likely to contribute to students' deep approach to learning while summative assessment is likely to contribute to their surface approach. However students tend to swing between different learning approaches in response to various factors. While changing education culture is highly needed in order to accommodate assessment effect on students learning and direct it to enhance deeper approach to learning, assessment impact on students' learning will continue to be strongly correlated with the magnitude of the severity of consequences associated with its implementation.

Unless a full understanding to the effect of various personal and contextual factors on students learning is established, students will continue to swing between different learning approaches. Several of these factors have been partially explored, such as assessment function, clinical supervisors and supervision, and constructive alignment. There are many others that have yet to be explored in connection to students' perception of their assessment and the adopted learning approaches. This exploration should aim to have a clear guide on how to adopt a customized assessment to education culture, environment and recourses that can positively influence students' learning.

The publication of this supplement has been made possible with the generous financial support of the Dr Hamza Alkholi Chair for Developing Medical Education in KSA.

Declaration of interest: The authors report no declarations of interest.

\section{References}

Al Kadri HM, Al-Moamary MS, Al Takroni H, Roberts C, van der Vleuten C. 2011a. Self-assessment and students' study strategies in a community of clinical practice: A qualitative study. Riyadh, Saudi Arabia, KSAU-HS, COM (Unpublished data)

Al Kadri HM, Al-Moamary MS, Elzubair M, Magzoub ME, Almutairi A, Roberts C, van der Vleuten C. 2011b. Exploring factors affecting undergraduate medical students' study strategies in the clinical years: A qualitative study. Adv Health Sci Educ Theory Pract 16(5):553-567.
Al Kadri HM, Al-Moamary MS, van der Vleuten C. 2009. Students' and teachers' perceptions of clinical assessment program: A qualitative study in a PBL curriculum. BMC Res Notes 2:263.

Baeten M, Dochy F, Struyven K. 2008. Students' approaches to learning and assessment preferences in a portfolio-based learning environment. Instruct Sci 36:359-374.

Biggs JB. 1970. Faculty pattern in study behaviour. Aust J Psychol 22:161-174.

Biggs JB. 1976. Dimensions of study behaviour: Another look at ATI. Br J Educ Psychol 46:68-80.

Biggs J. 1993. What do inventories of students' learning processes really measure? A theoretical review and clarification. Br J Educ Psychol 63:3-19.

Biggs J. 1999. Teaching for quality learning at university. Buckingham: SRHE and Open University Press.

Black P, Wiliam D. 1998a. Assessment and classroom learning. Assess Educ 5:7-74.

Black P, Wiliam D. 1998b. Inside the black box: Raising standards through classroom assessment. Phi Delta Kappan 80:139-149.

Boud D. 1995. Enhancing learning through self-assessment. London: Kogan Page.

Broadbent DE. 1966. The well-ordered mind. Am Educ Res J 3:281-295.

Broekkamp H, Bernadette HAM, HOUT-WOLTERS V. 2007. Students' adaptation of study strategies when preparing for classroom tests. Educ Psychol Rev 19:401-428.

Cilliers FJ, Schuwirth LW, Adendorff HJ, Herman N, van der Vleuten CP. 2010. The mechanism of impact of summative assessment on medical students' learning. Adv Health Sci Educ Theory Pract 15:695-715.

Cilliers FJ, Schuwirth LW, Herman N, Adendorff HJ, van der Vleuten CP. 2011. A model of the pre-assessment learning effects of summative assessment in medical education. Adv Health Sci Educ Theory Pract. DOI: $10.1007 /$ s10459-011-9292-5.

Cowie B, Bell B. 1999. A model of formative assessment in science education. Assess Educ 6:101-116.

Dochy F, Segers M, Gijbels D, Struyven K. 2006. Assessment engineering: Breaking down barriers between teaching and learning, and assessment. In: Boud DJ, Falchikov N, editors. Rethinking assessment in higher education: Learning for the longer term. New York: Routledge. pp 87-100.

Edstrom K, Gaidi KE, Hallstrom S, Kuttenkeuler J. 2006. Integrated assessment of disciplinary, personal and interpersonal skills - student perceptions of a novel learning experience. In: Rust C, editor. Improving student learning: Improving student learning through assessment. Oxford: OCSLD

Entwistle NJ, Entwistle DM. 1970. The relationships between personality, study methods and academic performance. $\mathrm{Br} \mathrm{J}$ Educ Psychol 40:132-141.

Gijbels D, Segers M, Struyf E. 2008. Constructivist learning environments and the (im)possibility to change students' perceptions of assessment demands and approaches to learning. Instruct Sci 36:431-443.

Kadri HM, Al-Moamary MS, Magzoub ME, Roberts C, Vleuten CPM. 2011. Students' perceptions of the impact of assessment on approaches to learning: A comparison between two medical schools with similar curricula. Int J Med Educ 2:44-52.

Klenowski V. 1996. Connecting assessment and learning. Paper presented at the British Educational Research Association annual conference, Lancaster University.

Knight PT. 2001. A briefing on key concepts: Formative and summative, criterion and norm-referenced assessment. LTSN Higher Education Academy Generic Centre Assessment Series. New York: Learning and Teaching Support Network.

Koh LC. 2008. Refocusing formative feedback to enhance learning in pre-registration nurse education. Nurs Educ Pract 8:223-230.

Leung SF, Mok E, Wong D. 2008. The impact of assessment methods on the learning of nursing students. Nurs Educ Today 28:711-719.

Luwel K, Lemaire P, Verschaffel L. 2005. Children's strategies in numerosity judgment. Cogn Dev 20:448-471.

Marton F, Saljo R. 1976. On qualitative differences in learning: I. Outcome and process. Br J Educ Psychol Rev 46:4-11. 
Marton F, Saljo R. 1997. Approaches to learning. In: Marton F, Hounsell DJ, Entwistle NJ, editors. The experience of learning. 2nd ed. Edinburgh, UK: Scottish Academic. pp 36-55.

Mattick K, Knight L. 2007. High-quality learning: Harder to achieve than we think? Med Educ 41:638-644.

Mattick K, Knight L. 2009. The importance of vocational and social aspects of approaches to learning for medical students. Adv Health Sci Educ Theory Pract 14:629-644.

Mckeachie WJ. 1990. Research on college teaching: The historical background. J Educ Psychol 82:189-200.

Newble DI. 1988. Eight years' experience with a structured clinical examination. Med Educ 22:200-204.

Newble D, Jaeger K. 1983. The effect of assessment and examination on the learning of medical students. Med Educ 17:165-171.

Nijhuis J, Segers M, Gijselaers W. 2005. Influence of redesigning a learning environment on student perceptions and learning strategies. Learn Environ Res 8:67-93.

Norman G, Neville A, Blake JM, Mueller B. 2010. Assessment steers learning down the right road: Impact of progress testing on licensing examination performance. Med Teach 32:496-499.

Prescott LE, Norcini JJ, Mckinlay P, Rennie JS. 2002. Facing the challenges of competency-based assessment of postgraduate dental training: Longitudinal Evaluation of Performance (LEP). Med Educ 36:92-97.

Ramsden P. 1984. The context of learning. In: Marton F, Hounsell D, Entwistle N, editors. The experience of learning. Edinburgh, Scotland: Scottish Academic Press. pp 144-164.

Reay D, Wiliam D. 1999. 'I'll be a nothing': Structure, agency and the construction of identity through assessment. Br Educ Res J 25:345-354.

Rushton A. 2005. Formative assessment: A key to deep learning? Med Teach 27:509-513.

Santy J, Mackintosh C. 2000. Assessment and learning in post-registration nurse education. Nurs Stand 14:38-41.

Schmeck R, Ribich F, Ramanaiah N. 1977. The development of a self-report inventory for assessing individual differences in learning processes. Appl Psychol Meas 1:413-431.

Schunn CD, Reder LM. 1998. Strategy adaptivity and individual differences. In: Medin DL, editor. The psychology of learning and motivation., Vol. 38. New York, NY: Academic. pp 115-154.

Schuwirth LW, van der Vleuten C. 2004. Merging views on assessment. Med Educ 38:1208-1210
Schuwirth LW, van der Vleuten CP. 2011. Programmatic assessment: From assessment of learning to assessment for learning. Med Teach 33:478-485.

Scouller K. 1996. July Influence of assessment method on students' learning approaches, perceptions and preferences: The assignment essay versus the short answer examination. Perth, Australia: HERDSA.

Segers M, Martensa R, Bossche P. 2008. Understanding how a case-based assessment instrument influences student teachers' learning approaches. Teach Teach Educ 24:1751-1764.

Segers M, Nijhuis J, Gijselaers W. 2006. Redesigning a learning and assessment environment: The influence on students' perceptions of assessment demands and their learning strategies. Stud Educ Eval 32:223-242.

Shen J, Hiltz SR, Bieber M. 2008. Learning strategies in online collaborative examinations. IEEE Trans Prof Commun 51(1):63-78.

Sluijsmans DMA, Brand-Gruwel S, van Merriënboer J. 2002. Peer assessment training in teacher education. Assess Eval High Educ 27:443-454

Struyven K, Dochy F, Janssens S, Schelfhout W, Gielen S. 2006. On the dynamics of students' approaches to learning: The effects of the learning/teaching environment. Learn Instruct 16:279-294.

Tang C. 1994. Effects of modes of assessment on students' preparation strategies. In: Gibbs $\mathrm{G}$, editor. Improving student learning: Theory and practice. Oxford: Oxford Centre for Staff Development. pp 151-170.

Tillema H. 2001. Portfolios as developmental assessment tools. Int J Train Dev 5:126-135.

Tiwari A, Lam D, Yuen KH, Chan R, Fung T, Chan S. 2005. Student learning in clinical nursing education: Perceptions of the relationship between assessment and learning. Nurse Educ Today 25:299-308.

Torrance H, Prayor J. 1998. Investigating formative assessment: Teaching, learning and assessment in the classroom. Buckingham: Open University Press.

van der Vleuten CP, Schuwirth LW. 2005. Assessing professional competence: From methods to programmes. Med Educ 39:309-317.

Vermunt JD. 1996. Metacognitive, cognitive and affective aspects of learning styles and strategies: A phenomenographic analysis. High Educ 31:25-50.

Vermunt JD. 1998. The regulation of constructive learning processes. Br J Educ Psychol 68:149-171. 